http://jmscr.igmpublication.org/home/ ISSN (e)-2347-176x ISSN (p) 2455-0450 crossref DOI: https://dx.doi.org/10.18535/jmscr/v9i4.16

\title{
Clinical Evaluation of Giddiness: Our Experience
}

\author{
Author \\ Dr Ramchandra
}

Department of ENT, M. R. Medical College, Kalaburagi, Karnataka, India

\begin{abstract}
Background: Vertigo (Dizziness, giddiness, Imbalance, light-headedness, oscillopsia, spinning of head) is the most distressing symptom experienced by the patients and frequently present themselves in many specialty clinics like cardiology, neurology, general medicine, geriatric and ENT and these individual specialties have different strategies for evaluating vertigo in a particular pattern of their expertise.

But due to varied etiologies, it is not easily diagnosed and often patient are referred to different specialties and being subjected to expensive and inappropriate investigations. Such an approach leads to an unsatisfied patient who waits for months to get an appropriate diagnosis of vertigo.

Therefore, there is a need to take a careful, dedicated and committed history as well as thorough clinical examination to establish the cause for giddiness.

Aims and Objective: To evaluate all cases presenting to OPD with giddiness \& to know the peripheral, central and other causes of vertigo.

Material and Methods: This study included 50 patients who presented with primary complaints of vertigo or dizziness.

All patients were subjected to careful history taking and thorough clinical examination was done.

Results: Of the 50 patients presenting to OPD, a peripheral cause was seen in 25 patients. 19 patients were diagnosed with Benign positional paroxysmal vertigo (BPPV), whereas 06 patients showed a central lesion of the vestibular system.

Conclusion: Careful history taking and thorough clinical assessment of patients is required for reasonable evaluation of vertigo. Though vestibular causes are important, it is essential to have a broad view of the various causes of vertigo so that serious and life threatening central causes are not missed out \& should be kept in mind while evaluation.

Keywords: Giddiness, Peripheral vertigo, Central Vertigo.
\end{abstract}

\section{Introduction}

Vertigo is one of the most complicated morbid symptoms, which has immense psychological impact on patient's life. It is a distressing feeling ranging from light headedness to rotatory reeling sensation. On an average $2 \%$ of the consultation is due to giddiness and it increases to as much as $30 \%{ }^{1}$. Epidemiological studies have shown that vertigo and balance disorder affect $10-15 \%^{2}$ of the general population.

The symptom may result from a disease due to various causes (with both the peripheral or central vestibular or retro-vestibular etiology), differing in severity (from minor to very severe) and prevalence, while its early diagnosis can be of immense importance for further fate of the affected person $^{(3,4)}$. Prior studies have shown that 
lifetime prevalence was $7.5 \%$ and incidence was $1.5 \%$. Nearly $80 \%$ of symptomatic people sought consultation. There was association of tinnitus, depression, cardiovascular problems, hypertension and dyslipidemia. Female sex had an independent effect on vertigo. ${ }^{5}$

Patients often visit multiple clinicians in different specialties (general practitioners, General physicians, neurologists and otolaryngologists). As a result, they undergo multiple consultations and investigations before a definitive diagnosis is made. This delay has a severe adverse impact on their work, family, and hence quality of life. Half of the patients affected

by dizziness feel that their efficiency at work has substantially dropped and one-quarter of patients even give up or change their work as a result of dizziness. Therefore, there is a need to take a careful, dedicated and committed history as well as thorough clinical examination to establish the cause for giddiness.

The present study is thus centered on the comprehensive evaluation of giddiness using committed history as well as thorough clinical examination to establish the cause for giddiness and to know various causes \& proportion of peripheral and central causes of Vertigo.

Balance disorders can arise from abnormal signaling from one or more sensory systems including the visual, proprioceptive and vestibular systems.

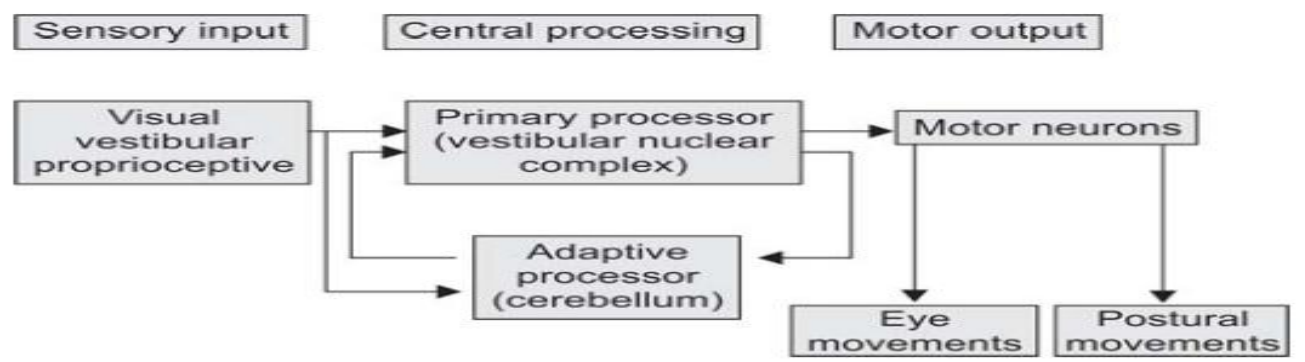

Hence, anatomy and physiology of the vestibular system is important for better understanding the causes, diagnosis, and treatment of vertigo ${ }^{[6]}$.

The vestibular system is broadly categorized into both peripheral and central components. Vertigo is classified into either peripheral or central depending on the location of the dysfunction of the vestibular pathway, although it can also be caused by psychological factors.

\section{Peripheral Vertigo}

Vertigo caused by problems with the inner ear or vestibular system, which is composed of the semicircular canals, the otolith (utricle and saccule), and the vestibular nerve is called "peripheral", "otologic" or "vestibular" vertigo.

\section{Common causes of Peripheral Vertigo}

\begin{tabular}{|l|c|}
\hline Head trauma & Perilymph fistula \\
\hline Benign paroxysmal positional vertigo & Syphilis \\
\hline Meniere's disease & Herpes zoster oticus \\
\hline Vestibular neuronitis & Cholesteatoma \\
\hline Labyrinthitis & Acoustic neuroma \\
\hline Vestibulotoxic drugs & Otosclerosis \\
\hline
\end{tabular}

\section{Central Vertigo}

Vertigo that arises from injury to the balance centres of the central nervous system (CNS) is generally associated with less prominent movement illusion and nausea than vertigo of peripheral origin. Central vertigo has accompanying neurologic deficits (such as slurred speech and double vision), and pathologic nystagmus (which is pure vertical/torsional).

Common causes of central vertigo:

- Vertebrobasilar insufficiency

- Posterior inferior cerebellar artery syndrome

- Basilar migraine

- Cerebellar disease

- Multiple sclerosis

- Cervical vertigo

- Tumours of brainstem and fourth ventricle

- Epilepsy ${ }^{[7]}$

Systemic causes of vertigo and dizziness ${ }^{[8]}$ 
Drugs and toxins (including anticonvulsants, hypnotics, antihypertensive, alcohol, analgesics, tranquilizers, quinine, ethacrynic acid, aminoglycoside antibiotics (especially streptomycin, gentamicin), salicylates, benzene, arsenic, arsine.

Hypotension, presyncope (including primary cardiac causes and postural hypotension from a wide variety of causes).

Infectious diseases (including syphilis, viral and other bacterial meningitides, and systemic infection).

Endocrine diseases (including diabetes and hypothyroidism).

Vasculitis (including collagen vascular disease, giant cell arteritis, and drug-induced vasculitis)

Other systemic conditions (including hematological disorder [polycythemia, anemia, and dysproteinemia], sarcoidosis, granulomatous disease, and systemic toxins).

\section{History}

When eliciting the history, it is important to have leading questions like "Are you feeling lightheadedness"e or "is the world spinning around you". A confident answer in such question can give a diagnosis in most of the cases before examining the patient. Three out of four patients can be diagnosed correctly with history alone ${ }^{9}$.

Duration and severity:

The duration of vertigo can last from seconds to days or can even last for months. Based on the duration it is helpful to arrive at a reasonable conclusion. Usually peripheral type of vertigo is very severe and lasts for shorter duration.

\section{Is it peripheral or central or other types}

Peripheral vertigo is caused by otological causes or neuro otological causes. Longer duration is suggestive of central causes and shorter bursts of vertigo are more likely due to peripheral causes. The provocation factors and duration will give clues to diagnosis. Rotary illusion is highly associated with peripheral type of vertigo. The presence of nystagmus especially rotary type and to sides can be more suggestive of peripheral as against up beating or a down beating one.

\section{Provoking Factors}

Various positional changes like, bending down and coming up, turning to sides on bed, hyperextending neck are suggestive of peripheral vertigo. At the same time rhinitis or a viral fever prior to the episode may point towards vestibular neuronitis or an infectvie labrynthitis. If the patient identifies trigger factors in an established migraine condition, this will point towards migrainous vertigo.

Vertigo due to straining, barotrauma like blowing of nose will point towards perilymphatic fistula. The phenomenon of Tullio's should also be borne in mind while dealing with provoking factors.

A history of stress is important, as is a history of psychiatric illness. A panic attack can also mimic vertigo in some stressed patients.

\section{Associated Symptoms}

The presence of hearing loss, along with vertigo (except in cases with CVA (cerebrovascular accident) involving posterior cerebral circulation), is usually peripheral in origin. Nausea and vomiting is pronounced in peripheral vertigo when compared with central vertigo.

Neurological symptoms like loss of memory, ataxia, sensory involvement, disturbances in vision are more seen in central causes. It is interesting to note that about $35 \%$ of migraine patients suffer from vertigo ${ }^{10}$.

\section{Medical History}

Presence of associated illnesses like diabetes, hypertension, dyslipidemia, family history of cerebrovascular accidents etc. also provide clue towards diagnosis

\section{Materials and Methods}

The present study was carried out on 50 Patients with primary complaints of vertigo attending the ENT OPD at Basaveshwar Teaching and General Hospital Gulbarga. The study was conducted over 


\section{JMSCR Vol||09||Issue||04||Page 93-99||April}

a period of one year. Ethical clearance was obtained from the Institutional Ethical Committee. An informed consent was obtained from all the patients before the start of study.

\section{Methodology}

All patients were subjected to comprehensive history taking according to the proforma and detailed Otorhinolaryngology examination carried out in all the patients. General examination,

Systemic examination, clinical cerebellar tests, tests to evaluate vestibulo-ocular and vestibule Spinal systems and provocative test like Dix Hallpike were done.

Spontaneous nystagmus test, gaze test, pendulum tracking test, positional test, Dix Hallpike test, Calorie test were performed on all the patients.

\section{Result}

Table-1: Age Distribution

\begin{tabular}{|l|c|c|}
\hline AGE (In Years) & No. of Patients & Percentage \\
\hline$<20$ & 4 & $8 \%$ \\
\hline $21-30$ & 8 & $16 \%$ \\
\hline $31-40$ & 12 & $24 \%$ \\
\hline $41-50$ & 14 & $28 \%$ \\
\hline $51-60$ & 8 & $16 \%$ \\
\hline$>60$ & 4 & $8 \%$ \\
\hline Total & $\mathbf{5 0}$ & $\mathbf{1 0 0 \%}$ \\
\hline
\end{tabular}

The youngest patient in our study was of 18 years and the oldest was 70 years. Most of the patients belonged to 4 th decade i.e. $41-50$ years. The average age was $\underline{41.4}$ years with standard deviation of \pm 2.2 years.

Table-2: Sex Distribution

\begin{tabular}{|l|c|c|}
\hline Sex & No. of patients & Percentage \\
\hline Male & 27 & $54 \%$ \\
\hline Female & 23 & $46 \%$ \\
\hline
\end{tabular}

Of the total 50 patients, 27(54\%) were males and $23(46 \%)$ were females. Thus male to female ratio was 1.17:1 $(\mathrm{M}>\mathrm{F})$.

Table-3: Presenting Complaints

\begin{tabular}{|l|c|c|}
\hline $\begin{array}{l}\text { Presenting } \\
\text { Complaints }\end{array}$ & $\begin{array}{c}\text { No. of } \\
\text { Patients }\end{array}$ & Percentage \\
\hline Swaying & 8 & $16 \%$ \\
\hline Unsteadiness & 3 & $6 \%$ \\
\hline Light Headedness & 1 & $2 \%$ \\
\hline Spinning & 20 & $40 \%$ \\
\hline Imbalance & 17 & $34 \%$ \\
\hline Blackouts & 1 & $2 \%$ \\
\hline
\end{tabular}

In our study out of 50 patients, most common presentation was spinning sensation seen in 20 patients, followed by imbalance among 17 patients. Rest 08 patients complained of Swaying, 03 patients had unsteadiness, 01 patients complained of light headedness \& 01 patients had Blackouts. In our study no patient presented with syncope.

Table-4: Associated Symptoms

\begin{tabular}{|l|c|c|}
\hline $\begin{array}{l}\text { ASSOCIATED } \\
\text { SYMPTOMS }\end{array}$ & $\begin{array}{c}\text { No. of } \\
\text { Patients }\end{array}$ & Percentage \\
\hline NAUSEA & 21 & $42 \%$ \\
\hline VOMITING & 11 & $22 \%$ \\
\hline HEADACHE & 2 & $4 \%$ \\
\hline EAR ACHE & 3 & $6 \%$ \\
\hline HEARING LOSS & 4 & $8 \%$ \\
\hline AURAL FULLNESS & 1 & $2 \%$ \\
\hline TINNITUS & 08 & $16 \%$ \\
\hline
\end{tabular}

Out of 50 patients evaluated, most common associated symptom was Nausea in 21 patients followed by Vomiting in 11 patients. Rest 02 patients complained of headache and 03 patients complained of earache, 04 patients had hearing loss, aural fullness among 01 patients \& 08 patients complained of associated tinnitus. In our study, More than $50 \%$ of patient had associated ear symptoms Suggestive of Peripheral cause.

Table-5: Other Co-Morbidities

\begin{tabular}{|l|c|c|}
\hline Other Ailments & No. of patients & Percentage \\
\hline Hypertension & 18 & $36 \%$ \\
\hline Diabetes mellitus & 10 & $20 \%$ \\
\hline $\begin{array}{l}\text { Neurological } \\
\text { disorder }\end{array}$ & 9 & $18 \%$ \\
\hline $\begin{array}{l}\text { Head \& neck } \\
\text { trauma }\end{array}$ & 7 & $14 \%$ \\
\hline Others & 6 & $12 \%$ \\
\hline
\end{tabular}

Out of 50 patients, associated Co-morbidities include hypertension among 18 patients, 10 patients had Diabetes mellitus, 09 patients neurological disorder and history of head \& neck trauma among 07 patients and 06 patients had other causes like vitamin D3 deficiency, Hypothyroidism, vitamin B12 Deficiency and Gastro esophageal reflux disease( GERD). 
Table-6: Clinical Findings

\begin{tabular}{|l|c|c|}
\hline Clinical test & No. of patients & Percentage \\
\hline Fistula test & 0 & 0 \\
\hline $\begin{array}{l}\text { Spontaneous } \\
\text { nystagmus }\end{array}$ & 09 & $18 \%$ \\
\hline Head-Impulse test & 06 & $12 \%$ \\
\hline Dix-Hallpike test & 19 & $38 \%$ \\
\hline Supine-Roll test & 00 & $00 \%$ \\
\hline Unterberger test & 10 & $20 \%$ \\
\hline Romberg's test & 3 & $6 \%$ \\
\hline $\begin{array}{l}\text { Straight line walking } \\
\text { test }\end{array}$ & 2 & $4 \%$ \\
\hline Dysdiadochokinesia & 1 & $2 \%$ \\
\hline
\end{tabular}

On clinical evaluation of 50 patients with vertigo, Spontaneous nystagmus was positive in 09 patients, Head impulse test positive in 06 patients, Unterberger test was positive in 10 patients all clinically suggestive of peripheral cause.

Dix- Hallpike test (posterior canal BPPV) showed nystagmus in 19 patients, clinically suggestive of Benign positional paroxysmal vertigo (BPPV).

Supine roll test (Lateral canal BPPV) showed no nystagmus. Fistula test was not positive ruling out superior semicircular canal dehiscence / fistula.

Romberg's test positive was positive in 03 patients, straight line walking test was positive in 02 patients \& Dysdiadochokinesia was seen in 01 patient all clinically suggestive of central cause.

Table-7: Caloric Test Findings

\begin{tabular}{|l|c|c|}
\hline $\begin{array}{l}\text { Calorie test } \\
\text { findings }\end{array}$ & No. of patients & Percentage \\
\hline Normal response & 10 & $20 \%$ \\
\hline $\begin{array}{l}\text { Hypoactive } \\
\text { response }\end{array}$ & 36 & $72 \%$ \\
\hline $\begin{array}{l}\text { Hyperactive } \\
\text { response }\end{array}$ & 04 & $8 \%$ \\
\hline
\end{tabular}

Among calorie ENG findings, showed Hypoactive response in 36 patients, hyperactive response in 04 cases, normal response in 10 patients.
Out of 50 cases, a peripheral cause was seen in 44 patients. Of which Acute Labyrinthitis in 11 cases, Vestibular neuronitis in 05 cases, benign positional paroxysmal vertigo (BPPV) in 19 cases, Meniere's disease in 02 cases, labyrinthine dysfunction(Chronic labyrinthine dysfunction \& Traumatic labyrinthine concussion) in 03 cases.

Other causes include Migranous vertigo, psychogenic vertigo in one each and Cervicogenic vertigo among 02 cases.

Table-8: Peripheral Causes

\begin{tabular}{|c|c|c|}
\hline \multicolumn{2}{|c|}{ Peripheral causes } & No of cases \\
\hline \multicolumn{2}{|c|}{ Acute Labyrinthitis } & 11 \\
\hline \multicolumn{2}{|c|}{ Vestibular neuronitis } & 05 \\
\hline \multicolumn{2}{|c|}{$\begin{array}{l}\text { Benign positional paroxysmal } \\
\text { vertigo(BPPV) }\end{array}$} & 19 \\
\hline \multicolumn{2}{|c|}{ Meniere's disease } & 02 \\
\hline \multirow[t]{2}{*}{$\begin{array}{l}\text { Labyrinthine } \\
\text { dysfunction }\end{array}$} & $\begin{array}{l}\text { Chronic } \\
\text { labyrinthine } \\
\text { dysfunction }\end{array}$ & 02 \\
\hline & $\begin{array}{l}\text { Traumatic } \\
\text { labyrinthine } \\
\text { concussion }\end{array}$ & 01 \\
\hline \multirow[t]{3}{*}{ Others } & $\begin{array}{l}\text { Migranous } \\
\text { vertigo }\end{array}$ & 01 \\
\hline & $\begin{array}{l}\text { Psychogenic } \\
\text { vertigo }\end{array}$ & 01 \\
\hline & $\begin{array}{l}\text { Cervicogenic } \\
\text { vertigo }\end{array}$ & 02 \\
\hline
\end{tabular}

Among central causes included, cerebellar lesion among 02 cases, brainstem lesion in 02 cases and cerebrovascular events in 02 cases.

Table-9: Central Causes

\begin{tabular}{|l|l|}
\hline Central causes & No of cases \\
\hline Cerebellar lesion & 02 \\
\hline Brain stem lesion & 02 \\
\hline Vascular causes & 02 \\
\hline
\end{tabular}

\section{Discussion}

Clinical findings of 50 patients complaining of vertigo or dizziness were documented in this study and the causes were differentiated to peripheral and central causes of vertigo. 


\section{Presenting Complaints}

Herr RD \& et al (1989) ${ }^{11}$ in his study found spinning, imbalance, swaying, unsteadiness, light headedness as the main complaints. Complaints of patients in our study are comparable to above study.

In our study Romberg's test came positive in $3(5 \%)$ patients. Romberg's test can also be positive in healthy subjects, and this test cannot distinguish between vestibular deficit and other causes. Romberg's test is less reliable in diagnosis of vertigo. Jacobson $\mathrm{GP}^{12}$ and et al suggested that Romberg's test is insensitive to consider it as a screening measure for vestibular impairment. .

In our study Unterberger test came positive in 10 (20\%) patients of peripheral vestibulopathy. Bonanni and Newton 1998 suggested that Unterberger stepping test is not a reliable screening tool for peripheral vestibular asymmetry as this test gives poor test-retest reliability and should be used in combination with other tests ${ }^{13}$. Rudert H (1977), Hickey SA et al (1990) also stated that Unterberger test showed no significance in diagnosis of vestibular dysfunction 14,15

\section{Dix-Hallpike test}

\begin{tabular}{|l|c|}
\hline Study & $\begin{array}{c}\text { Positive Dix Hallpike } \\
\text { maneuver- Percentage (\%) }\end{array}$ \\
\hline $\begin{array}{l}\text { Helen S. Cohen \& et al } \\
(2014)^{16}\end{array}$ & 40 \\
\hline $\begin{array}{l}\text { Sharma V \& Shah RK } \\
(2014)^{17}\end{array}$ & 54.03 \\
\hline $\begin{array}{l}\text { M. Panduranga Kamath \& } \\
\text { et al (2015) }\end{array}$ & 33 \\
\hline Our Study & $38 \%$ \\
\hline
\end{tabular}

\section{Table-10}

In our study, 19 patients (38\%) were positive for Dix Hallpike maneuver which is comparable to other studies. Nystagmuses on Dix Hallpike maneuver in these patients were typically latent and fatigable. Positive Dix Hallpike maneuver is diagnostic of benign paroxysmal positional vertigo (BPPV).
Cerebellar test like Dysdiadochokinesia is positive in 01 patient in our study which is a sign for cerebellar disease. These patients were eventually diagnosed with central lesion causing vertigo.

In our study spontaneous nystagmus was seen in 09 patients, which were seen on eye examination, typically latent and fatigable; suggestive of peripheral vestibular disorder.

Almost all the cases evaluated in our department were cases with primary complaint of vertigo \& also referred from other department and hence on evaluation had peripheral or central cause of vertigo. We didn't had case presenting with presyncope.

\section{Conclusion}

An attempt has been made in our study to document clinical findings of patients complaining of vertigo and to differentiate causes of vertigo into peripheral and central.

Careful history taking and thorough clinical assessment of patients is required for reasonable evaluation of vertigo. Though vestibular causes are important, it is essential to have a broad view of the various causes of vertigo so that serious and life threatening central causes are not missed out $\&$ should be kept in mind while evaluation.

There is a need for systematic examination and a reasonable treatment plan for elderly as there is a high chance of fall and thereby increasing the morbidity, mortality and affecting the mobility of the patients. Emerging geriatric populations should be kept in mind while diagnosis and treatment protocols are standardized throughout the country.

\section{References}

1. Colledge NR, Wilson JA, Macintyre CCA, MacLennan WJ. The prevalence and characteristics of dizziness in an elderly community. Age Aging. 1994;23:117-20.

2. Nazareth I, Yardley L, qwen N, Luxon R. Outcomes of symptoms of dizziness in general practice community sample. Fam Pract 1999; 16:616-8 
3. Józefowicz-Korczyńska M, Łukomski M, Pajor A. Electronystagmographic evaluation of the vestibular organ condition in patients with tinnitus and cervical spine degeneration. Otolaryngol Pol 2004; 58(2):349-53 [in Polish].

4. Olszewski J, Repetowski M. Clinical analysis of cervical vertigo patients in the own material. Otolaryngol Pol 2008; 62(3): 283-7.

5. Neuhauser HK, von Brevern M, Radtke A, Lezius F, Feldmann M, Ziese T, Lempert T. Epidemiology of vestibular vertigo A neurotologic survey of the general population. Neurology Sep. 2005;65(6):898-9.

6. Gulya, A. .J, Minor, L. .B, Poe, D. .S. Glasscock- Shambaugh Surgery Of The Ear. (6th ed.). Shelton, Connecticut: People's Medical Publishing House - USA; 2010: 113-135.

7. Dhingra, P. Disease of ear, nose and throat. New Delhi: Elsevier. 2004: 4th edition:45-47

8. Adolfo M. Bronstein et al. Oxford textbook of vertigo and imbalance. oxford university press.2013: 1ST edition: 01-21

9. Hoffman RM, Einstadter D, Kroenke K. Evaluating dizziness. Am J Med. 1999;107:468-78.

10. Cass SP, Furman JM, Ankerstjerne K, Balaban C, Yetiser S, Aydogan B. Migraine-related vestibulopathy. Ann Otol Rhinol Laryngol. 1997;106:182-9.

11. Bronstein AM, Golding JF, Gresty MA, Mandala M, Nuti D, Shetye A, Silove Y: The social impact of dizziness in London and Siena. JNeurol2010, 257:183-90.

12. Józefowicz-Korczyńska M, Łukomski M, Pajor A. Electronystagmographic evaluation of the vestibular organ condition in patients with tinnitus and cervical spine degeneration. Otolaryngol Pol 2004; 58(2):349-53 [in Polish].

13. Olszewski J, Repetowski M. Clinical analysis of cervical vertigo patients in the own material. Otolaryngol Pol 2008; 62(3): 283-7.

14. Tilikete C, Pelisson D. Ocular motor syndromes of the brainstem and cerebellum. Curropin neurol. Feb 2008; 21 (1):22-8.

15. Biswas, A. Clinical AudioVestibulometry for Otologists and Neurologists. (4th ed.). Mumbai, India: Bhalani Publishing House; 2009:177-224.

16. Gulya, A. .J, Minor, L. .B, Poe, D. .S. Glasscock- Shambaugh Surgery Of The Ear. (6th ed.). Shelton, Connecticut: People's Medical Publishing House - USA; 2010: 113-135.

17. Post Re, Dickerson LM. Dizziness: a diagnostic approach. Am Fam Physician. 2010; 82(4):361-369.

18. Dhingra, P. Disease of ear, nose and throat. New Delhi: Elsevier. 2004: $4^{\text {th }}$ edition:45-47. 